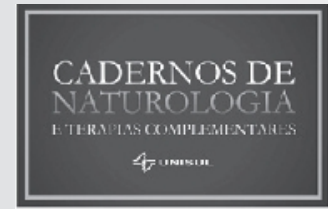

\section{AVALIAÇÃO DA UTILIZAÇÃO E DO EFEITO TERAPÊUTICO DAS TÉCNICAS DA NATUROLOGIA PARA O TRATAMENTO DA DOR}

\section{EVALUATION OF USE AND EFFECT OF NATUROLOGY THERAPEUTIC TECHNIQUES FOR THE TREATMENT OF PAIN}

RESUMO: Este artigo de revisão teve como objetivos o levantamento de artigos acadêmicos que trouxessem em seu conteúdo as técnicas utilizadas pela Naturologia para o tratamento da dor, e dados que demonstrassem a eficácia terapêutica ou não dessas técnicas. A partir de pesquisa nas bases de dados MEDLINE, SCIELO, LILACS, BIREME \& DEDALUS, o presente trabalho tabelou e analisou um total de 249 artigos referentes às seguintes técnicas: acupuntura, aromaterapia, auriculoterapia, fitoterapia, massagem, medicina complementar e alternativa, meditação, qigong, reiki, shiatsu, tai chi, terapias manuais e yoga. A análise dos dados trouxe à luz uma gama de resultados que fornecem aos profissionais da saúde, em particular da Naturologia, uma visão de como as referidas técnicas estão sendo utilizadas para aliviar diferentes tipos de dor. Embora os resultados obtidos nos artigos avaliados indiquem a eficácia dos tratamentos, ficou claro que há necessidade de um maior número de estudos que pesquisem os mecanismos de ação de várias das técnicas levantadas. Ressalta-se o evidente interesse de diversas nações, através de seus centros de pesquisa, pelo estudo do referido assunto.

\section{PALAVRAS-CHAVE}

Naturologia.

Dor.

Terapias Alternativas.

Medicina Complementar.

Analgesia.

Marina Augusta de Oliveira

- Bacharel em Ciências Biológicas - Modalidade Médica pela FMRPUSP; Mestrado e Doutorado em Universidade Anhembi Morumbi

Wagner Jose Dias

- Bacharel em Naturologia - UAM. Universidade Anhembi Morumbi

Bruna Rei Freitas em Fitoterapia pela UAM na Universidade Anhembi Morumbi Ciências (Farmacologia) - FMRP-USP.

- Bacharel em Naturologia, Especialista Graduação Modulada; Pós-Graduação em Medicina Ayurvédica e Extensão Universitária em Dor pela FMUSP.

CORRESPONDENTE

Wagner Jose Dias

Escola de Ciências da Saúde. Universidade Anhembi Morumbi. - Rua Dr. Almeida Lima, 1.134 - Mooca. São Paulo.

E-M A I L

wagner.jdias@gmail.com

Recebido: 17/03/2014

Revisado: 17/06/2014

Aprovado: 15/05/2015 


\begin{abstract}
This paper aimed to survey academic articles that evaluate techniques used by Naturology for pain treatment, and discuss data that would demonstrate or not the efficiency of these techniques. From research in the MEDLINE, SCIELO, LILACS, BIREME \& DEDALUS databases, this study analyzed a total of 249 articles related to the following techniques: acupuncture, aromatherapy, auriculotherapy, phytotherapy, massage, complementary and alternative medicine, meditation, qigong, reiki, shiatsu, tai chi, manual therapies and yoga. Data analysis shows several results that supply to healthcare professionals, in particular the Naturology, how these techniques are being used to relieve different types of pain. Although the results indicate the effectiveness of the treatments, it became clear that there is a need of a large number of studies who search mechanisms of action of these several techniques mentioned in this article. We emphasize the obvious interest from several nations, through its research centers, in the study of that subject.
\end{abstract}

KEYWORDS: Naturology. Pain. Alternative Therapies. Complementary Medicine. Analgesia.

\section{INTRODUÇÃO}

O presente trabalho realizou um levantamento bibliográfico das pesquisas científicas que utilizam diferentes técnicas utilizadas pela naturologia, para o tratamento da dor, assim como levantou dados que demonstram a eficácia terapêutica ou não dessas técnicas, fornecendo aos profissionais da naturologia um panorama a respeito do assunto. Segundo a Associação Internacional para o Estudo da Dor (IASP), dor é "uma experiência sensorial e emocional desagradável que é associada a lesões reais ou potenciais ou descrita em termos de tais lesões. A dor é sempre subjetiva e cada indivíduo aprende a utilizar este termo por meio de suas experiências"'.

O homem sempre foi atormentado pela dor, e as causas e os tratamentos para os estados dolorosos foram buscados desde as mais primitivas civilizações. Entretanto o estudo e o manejo da dor como sintoma e como doença ainda deixam muito a desejar ${ }^{2}$. A dor é um sintoma e uma das causas mais frequentes da procura por auxílio médico. A necessidade de se reconhecer a dor como $5^{\circ}$ sinal vital foi citada pela primeira vez em 1996 por James Campbell (Presidente da Sociedade Americana de Dor $)^{1}$.

A naturologia é uma ciência caracterizada pela mescla de racionalidades médicas, de filosofias e de técnicas de cura orientais, ocidentais, modernas e tradicionais. É um fenômeno decorrente da crise de paradigmas do mundo contemporâneo e da necessidade de revisão e ampliação dos modelos de prática médica vigentes. Apresenta-se como um conhecimento transdisciplinar filiado a modelos integrativos e complementares de atuação e atenção em saúde³.

\section{METODOLOGIA DE PESQUISA}

O presente trabalho realizou, através de um levantamento bibliográfico em bases de dados como MedLine, SciELO, Lilacs, Bireme e Dedalus a coleta de informações a partir de artigos publicados nos últimos cinco anos (foram excluídos os trabalhos anteriores ao ano de 2008). Foram pesquisados estudos clínicos com seres humanos, que apresentassem resumo e que demonstrassem a eficácia terapêutica ou não das técnicas utilizadas pela Naturologia para o tratamento da dor, utilizando como filtro de pesquisa as palavras-chaves: "complementary alternative therapy and pain". Para o devido embasamento teórico, foram utilizados literatura apropriada, sites e trabalhos de cunho acadêmico. Após a coleta, os dados relevantes foram organizados em tabelas.

\section{DOR E MEDICINA COMPLEMENTAR}

Apesar da globalização, inclusive do conhecimento, ainda há muitos pontos desconexos, principalmente no diálogo entre as ciências, mais especificamente, do que trata o presente trabalho, entre as ciências 
da saúde. Há que se entender que essa fragmentação por si só, é prejudicial ao ser humano, o qual necessita ser observado, cuidado e orientado de modo holístico e não apenas subdividido, como as ciências médicas têm feito no decorrer do tempo ${ }^{3}$. $\mathrm{O}$ reencontro dos saberes científicos, tradicionais e populares, proposto pela Naturologia, somado aos conhecimentos médicos específicos através de um diálogo multiprofissional e multidisciplinar, tem em vista trabalhar e entender cada vez mais o sinergismo positivo que essa somatória de conhecimentos proporciona aos pacientes, não só do referido trabalho sobre a dor, mas de toda e qualquer patologia ${ }^{2,3,4}$

A chamada Medicina Complementar e Alternativa (MCA) engloba o conjunto de técnicas subdivididas entre as Medicinas não Convencionais como, por exemplo, Medicina Tradicional Chinesa (MTC), Medicina Ayurvédica, Medicina Antroposófica, Medicina Botânica, Medicina Ioruba, Medicina Xamânica. Muitas dessas ciências necessitam ainda de um maior número de estudos para o entendimento de seus mecanismos de atuação, porém já não há como negar sua eficácia, não só pelas observações empíricas e relatos de pacientes, mas também pelo número crescente de estudos científicos realizados sobre o assunto. Corrobora esta análise a Política Nacional de Práticas Integrativas e Complementares (PNPIC), quando atende ao estímulo da Organização Mundial da Saúde (OMS), da utilização da Medicina Tradicional / Medicina Complementar e Alternativa nos sistemas de saúde de forma integrada às técnicas da Medicina Ocidental Moderna ${ }^{5}$.

A MCA sempre esteve presente no seio da humanidade, mas somente na década de 1960 passa a ser enfaticamente estudada, apresentando desde então, um número crescente de artigos publicados ${ }^{6}$.

As dores crônicas permitem discussões conceituais da Medicina Clássica, havendo a necessidade de argumentações que fogem do modelo biomédico clássico, com implicações filosóficas, sociais e emocionais, dai o modelo biopsicossocial. Assim, o pensamento de Shakespeare "todos são capazes de dominar a dor, exceto quem a sente" contraria as abordagens atuais, desde que um dos objetivos te- rapêuticos em uso é de técnicas que permitam aos pacientes conviver e interagir com a dor e o sofrimento. $\mathrm{O}$ homem da atualidade muitas vezes ainda encara a dor como uma série de conceitos complexos, entre eles os com conotações religiosas, sentimentos de culpa e expiação, que somente dificultam a abordagem e aumentam o sofrimento ${ }^{7}$.

A complexidade dos mecanismos anatômicos somados a ação de grande número de neurotransmissores envolvidos, interagindo ainda com aspectos socioculturais e psicológicos, fazem da dor um complexo campo de estudos. Quando estímulos ambientais físicos ou químicos intensos transformam-se em potenciais de ação e são transferidos para o Sistema Nervoso Central (SNC) pelas fibras nervosas periféricas, observa-se o primeiro passo dos eventos dolorosos, chamado de nocicepção, que envolve vários mecanismos: ativação de receptores, redução do limiar de geração de impulsos elétricos, inflamação neurogênica, ativação do sistema neurovegetativo simpático, sensibilização dos neurônios sediados nos gânglios sensitivos, mecanismos de modulação da dor, antinocicepção, cada qual envolvendo substâncias específicas (algiogênicas, peptídeos, derivados hormonais), promovendo o evento citado ${ }^{8}$.

$\mathrm{O}$ entendimento da dor não deve se limitar a sua expressão neurossensitiva, e sim também como uma mensagem emocional, uma metáfora perceptiva de sofrimento, de aflição ou mágoa. Durante o processo terapêutico devem ser considerados os comportamentos dos pacientes com dor crônica, reconhecidos como neuroses da dor: incapacidade física, depressão, ansiedade, visita a múltiplos médicos, utilização abusiva de drogas, dependência física e vícios de fármacos (principalmente de narcóticos), uso de tratamentos ineficientes ou potencialmente prejudiciais, incapacidade sócio profissional, envolvimentos judiciais, aposentadoria forçada, prejuízos financeiros e nas relações sociais, culminando algumas vezes com a rejeição familiar e frequentemente pelo sistema de saúde ${ }^{7}$.

A cultura é um tópico extremamente importante e que deve ser considerado frente aos quadros álgicos, pois exerce um poderoso efeito na tolerância ou 
não da dor. Cada cultura ou grupo social e, às vezes, até a família, tem uma linguagem de sofrimento única e própria, que é um conjunto complexo de termos próprios, por meio dos quais os indivíduos enfermos ou infelizes fazem com que as outras pessoas se tornem cientes de seus sofrimentos 9 .

A dor relacionada a questões emocionais e sentimentais está ligada a sensação dolorosa associada ao psiquismo do indivíduo, ao nervosismo, às tensões emocionais do cotidiano, à carência afetiva, à personalidade. Por isso torna-se necessário o entendimento da interação entre o sofrimento físico e mental, pois ela nos alerta da importância de valorizar as queixas de dor e do sofrimento, já que estes podem levar a depressão e a pensamentos suicidas 9 .

Pessoas religiosas e espiritualizadas (independentemente da religião) apresentam redução da queixa de dor. Isso se deve a várias respostas fisiológicas decorrentes de processos químicos desencadeados por reações emocionais. Hábitos saudáveis positivos e o aumento da autoestima proporcionam maior confiança, influenciando diretamente o lobo frontal cerebral e o eixo hipotálamo-pituitária-adrenal (HPA) interferindo nas respostas à dor e ao estresse. Também há o envolvimento do sistema límbico - circuito neuronal que controla o comportamento emocional e os impulsos motivacionais ${ }^{10}$.

\section{ACUPUNTURA}

Estudos neurofisiológicos da analgesia por acupuntura formulam várias hipóteses que levam a variadas conclusões, porém nenhuma definitiva que explique tal evento. Sabe-se que estão envolvidas no processo as fibras $A \alpha, A \beta, A \gamma, A \delta$, além das fibras $C$, e que quando estimuladas promovem o processamento do SNC (fibras nociceptivas projetam estímulos nos neurônios espinhais; ao passar pelo SNC esses estímulos são processados ou "modulados", resultando ou não em dor. A modulação é o resultado do equilíbrio de vários mecanismos inibidores e facilitadores em todo SNC - atividades simultâneas em outros lugares do SNC, fatores psicológicos, condicionamento, expectativa, medo, desejo, influências culturais e genéticas) que, dependendo do nível desses estímulos, desencadeará a liberação de uma cascata de substâncias (glutamato, aspartato, substância P, GABA, serotonina, noradrenalina, colecistocinina, oxitocina, peptídeos opióides - encefalinas, beta endorfinas, dinorfinas) que atuarão nas sinapses nervosas, modulando os limiares de dor ${ }^{11,12}$.

\section{AURICULOPUNTURA}

A teoria moderna se baseia na abundância de nervos (cranianos e espinais) que envolvem a orelha, cujas terminações nervosas são semelhantes a outras partes do corpo, resultando em uma habilidade de transmitir informações ao SNC, o qual repassa as mesmas ao sistema nervoso autônomo (SNA), que promove a regulação visceral pelo ramo auxiliar vago e fibras nervosas simpáticas do gânglio cervical superior, distribuídas na escafa ${ }^{12,13}$.

\section{QIGONG}

O mecanismo de atuação do Qi Gong se dá por duas vias: modificações de determinados parâmetros biológicos, verificados através de analises de sangue, como por exemplo, a facilitação à fabricação de certos hormônios (endorfinas, insulina, tireoidianos); a outra via é uma modificação do estado de consciência, como se o indivíduo estivesse em uma espécie de estado de transe, um verdadeiro estado hipnótico que favoreceria a harmonização do corpo e do espírito ${ }^{14,15}$.

\section{TERAPIAS MANUAIS}

No contato direto com as mãos do terapeuta (nível local), são afetados pela manipulação os tecidos moles (músculos, ligamentos, tendões, cápsulas articulares, faces articulares, pele e fáscia), através da facilitação do fluxo de fluidos (irrigação sanguínea e linfática)16,17.

$\mathrm{O}$ alívio da dor pode sobrevir quando os mecanoceptores musculares bloqueiam a sensação de dor transportada pelos neurônios sensoriais, a partir dos nociceptores. Durante a manipulação deve ser considerada a profundidade da sensibilização causada pela dor, pois quanto mais profundo o receptor, maior a sensibilidade central ${ }^{17}$. 
A manipulação não envolve apenas estruturas anatômicas, engloba o imaginário abstrato, as emoções, os pensamentos e toda a experiência de vida da pessoa. Pode promover alterações psicológicas (na percepção da imagem do corpo, no humor, no comportamento) e somáticas (psicossomáticas ou psicofisiológicas) - no tônus muscular, nas atividades autonômicas e viscerais, maior tolerância à dor, facilitação dos processos de cura e de autorregulação ${ }^{17}$.

\section{MEDITAÇÃO}

Pesquisas demonstram que no estado meditativo há um aumento de ondas alfa (de $9 \mathrm{a} 13 \mathrm{~Hz}$ - refletem estado de relaxamento), aumento de ondas teta (de $4 \mathrm{a} 8 \mathrm{~Hz}$ - refletem estado de sonolência e ou atenção), mostrando que o cérebro se encontra mais orientado internamente, alerta e atento. Em praticantes experientes se observou ondas cerebrais amplas (acima de $27 \mathrm{~Hz}$ ) sugerindo grande concentração e aumento da atividade neuronal, mesmo após a prática. As áreas cerebrais envolvidas são: lobos frontais anteriores, córtex cingulado anterior, sistema límbico (amigdala). Além da sensação de bem estar e conforto, efeitos na cognição e no humor, influências sobre o sistema imunológico, pode também atenuar sensação de desconforto (redução de ACTH, TSH, cortisol e aumento de GABA, dopamina, serotonina, endorfinas, acetilcolina) ${ }^{18}$.

\section{SHIATSU}

Terapia manual, cujas raízes são encontradas na China a mais de 5000 anos, que visa o restabelecimento do fluxo de energia vital $(K i)$, através da pressão exercida com os dedos (e ou outras partes do corpo) sobre o corpo do paciente, no trajeto dos meridianos (14 principais) onde se localizam pontos específicos para tal aplicação. A qualidade do "Ki" depende das condições dos estados: mental, emocional, físico e espiritual do indivíduo, onde desequilíbrios em qualquer desses estados, promovem bloqueios no fluxo de energia podendo desencadear problemas de saúde, cujo um dos principais sinais é a dor, que pode ser amenizada através da melhora de fluxo linfático e sanguíneo, alívio da tensão e con- sequentemente liberação da tríade dor-tensão-dor, devido ao relaxamento muscular e tendíneo, promovido pela técnica ${ }^{16,19,20}$.

\section{YOGA}

Prática milenar (estudos apontam mais de 2.000 anos) que visa eliminar possíveis bloqueios dos canais de energia, permitindo que o Prana (energia vital) flua livremente, promovendo harmonia física, psíquica e espiritual. Através da prática de asanas (posturas) ocorre a promoção da massagem em todas as partes do corpo, removendo fluidos impuros, como a linfa, permitindo que novos fluidos ricos em nutrientes cheguem às células. Ocorre também o massageamento dos órgãos internos, o que lhes conferem tonificação e melhora de função. A respiração profunda durante a prática permite uma maior oxigenação celular potencializando o trabalho. A estimulação de receptores sensoriais em todo o corpo levam informações ao cérebro, que após processadas, envia impulsos que movimentam os músculos e ativam as glândulas endócrinas ${ }^{19}$.

O estresse, ansiedade e a depressão, males comuns da atualidade, envolvem a ativação do sistema nervoso autônomo (SNA) (simpático) e do eixo neuroendócrino HPA. As alterações fisiológicas se dão através do SNA pelo hipotálamo, responsável pela regulação das funções básicas, manutenção e sobrevivência do organismo. A prática do yoga induz uma redução imediata nos níveis de cortisol e consequentemente do estresse, promovendo efeito direto no eixo HPA. O efeito ansiolítico da prática é comparado a medicamentos benzodiazepínicos por alguns pesquisadores ${ }^{18}$.

\section{REIKI}

Testes laboratoriais aferiram componentes eletrostáticos, magnéticos, eletromagnéticos, sônicos, térmicos e visuais desse campo, e todas as mensurações se harmonizam com os processos fisiológicos normais do corpo humano e os extrapolam, a fim de proporcionar um veículo para o funcionamento psicossomático. Sendo de natureza particulada, o campo de energia humano possui movimentos semelhantes aos de 
um fluido, e que quando, essas partículas carregadas se movimentam são cognominadas, pelos físicos, de plasma, e por obedecer a leis físicas, é considerado um estado entre a energia e a matéria ${ }^{21,22}$.

O mecanismo fisiológico de atuação da imposição de mãos não está elucidado. Há uma hipótese de que alterações hormonais podem estar diretamente relacionadas à melhora da função imunológica (exemplo: elevação do número de monócitos, diminuição da contagem de plaquetas, aumento da atividade citotóxica). Outra hipótese seria a de interação entre os campos bioeletromagnéticos próprios de cada ser vivo, assim como também, entre os campos que estão ao seu redor, como por exemplo: eletromagnético e gravitacional $^{23}$.

\section{AROMATERAPIA}

Os óleos essenciais podem desenvolver efeitos físicos e ou emocionais. Suas vias de atuação seriam: tópica, onde as moléculas são absorvidas pela pele alcançando a corrente sanguínea; e a outra via seria a olfativa, podendo atuar por dois caminhos: via pulmão, alcançando o sistema circulatório e via epitélio olfatório, influenciando o sistema límbico (ativação de memória, sentimentos e emoções). A ação analgésica e anti-inflamatória de alguns óleos essenciais, a nível físico-químico, se dá pela presença de substâncias como azuleno, germacranólides, silicato de metilo (um inibidor da biossíntese de prostaglandinas - mediadoras dos mecanismos da inflamação). Os óleos essenciais (Cedro, por exemplo) podem promover a estabilização da atividade mastocitária e a inibição da biossíntese de leucotrienos ${ }^{16,24,25,26,27,28}$.

\section{FITOTERAPIA}

A fitoterapia atual une os conhecimentos etnobotânicos e etnomédicos passados e farmacológicos básicos e clínicos modernos. Esta junção resultou na utilização da planta medicinal sob forma de extrato padronizado, tendo como apoio a tecnologia farmacêutica, obtendo-se a mesma qualidade dos medicamentos alopáticos padrões ${ }^{26,29,30}$.

Mesmo com todo avanço tecnológico e farmacêutico, muitos medicamentos sintéticos, não cumprem seus papéis pré-estabelecidos (inclusive em doenças crônicas) em contrapartida, os fitomedicamentos surgem como uma alternativa altamente positiva e com menores efeitos secundários. A ação analgésica de uma planta não está em um principio ativo isolado, mas na ação sinérgica de vários fitoconstituintes atuando através do mesmo mecanismo de ação ou por mecanismos diferentes ${ }^{31,32}$.

\section{TAI CHI CHUAN}

Por se tratar de um exercício aeróbico de intensidade baixa a moderada, sua prática regular, produz efeitos favoráveis nas funções: cardiovascular e pressão arterial, ventilatória, força muscular, equilíbrio, psicológica. Em praticantes portadores de artrite reumatoide, por exemplo, foi observado melhora no edema e dor articular, no tempo de caminhar e na força de pressão manual, não havendo deterioração clínica, além da possibilidade de manutenção da massa óssea e redução de sua perda em longo prazo Nos casos de osteoartrite, pode diminuir a severidade da dor e da disfunção articular ${ }^{33,34}$.

\section{RESULTADOS}

Os resultados obtidos no presente trabalho foram agrupados e tabelados conforme observados nas tabelas a seguir. Entre os artigos pesquisados (Tabela1) surpreende o número de trabalhos sobre o Reiki $(8,4 \%)$, que apesar de sua sutileza e parcial elucidação de seus mecanismos de ação, demonstra grande interesse científico. Já a técnica que se destaca, pelo maior número de artigos, é a auriculoterapia, por sua simplicidade e facilidade de aplicação, além da eficácia e parcial entendimento de sua atuação. A massagem poderia configurar entre as terapias manuais, porém o presente trabalho procurou enfatizá-la por ser muito utilizada pela naturologia e pela elevada porcentagem encontrada (10,9\%). A fitoterapia configura o menor número de artigos (2\%), devido à metodologia utilizada neste trabalho, que buscou pesquisas sobre a fitoterapia tradicional multissistêmica e não a fitoterapia ("farmacêutica") baseada em princípios ativos isolados. 
Tabela 1: Número de artigos pesquisados

\begin{tabular}{lcc}
\hline TÉCNICA & No DE ARTIGOS & \% \\
\hline Acupuntura & 19 & 7,6 \\
\hline Aromaterapia & 23 & 9,3 \\
\hline Aurículo & 28 & 11,3 \\
\hline Fitoterapia & 5 & 2,0 \\
\hline Massagem & 27 & 10,9 \\
\hline MCA & 22 & 8,8 \\
\hline Meditação & 24 & 9,6 \\
\hline Qigong & 8 & 3,2 \\
\hline Reiki & 21 & 8,4 \\
\hline Shiatsu & 18 & 7,2 \\
\hline Tai chi & 11 & 4,4 \\
\hline Terapias Manuais & 23 & 9,3 \\
\hline Yoga & 20 & 8,0 \\
\hline TOTAL & $\mathbf{2 4 9}$ & $\mathbf{1 0 0}$ \\
\hline
\end{tabular}

Tabela elaborada pelo autor, 2013.

Em relação ao tipo de metodologia utilizada na pesquisa dos artigos (Tabela 2) fica destacado o método quantitativo com $48,6 \%$ do total. Quantitativamente se destacam ainda as técnicas de massagem e yoga, ambas com 18 artigos cada, e a meditação e o reiki, 10 e 9 artigos respectivamente (meditação e reiki - não se destacam pelo número de artigos, mas surpreende pelo interesse científico em técnicas tão sutis).

Tabela 2: Tipo de metodologia utilizada na pesquisa dos artigos

\begin{tabular}{lccccccccc}
\hline & & & & & & \\
\hline Acupuntura & 12 & - & 3 & 4 & - & - & - & - \\
\hline Aroma & 8 & 5 & 1 & 4 & - & 5 & - & - \\
\hline Auriculo & 14 & 3 & 5 & 3 & - & 2 & 1 & - \\
\hline Fitoterapia & 4 & - & 1 & - & - & - & - & - \\
\hline Massagem & 18 & 3 & 1 & 4 & - & - & - & 1 \\
\hline MCA & 3 & 11 & 5 & 2 & 1 & - & - & - \\
\hline Meditação & 10 & 8 & 1 & 5 & - & - & - & - \\
\hline Qigong & 1 & 2 & 5 & - & - & - & - & - \\
\hline Reiki & 9 & 3 & - & 8 & - & 1 & - & - \\
\hline Shiatsu & 7 & 3 & 1 & 3 & - & 4 & - & - \\
\hline Tai chi & 2 & 1 & 2 & 6 & - & - & - & - \\
\hline Terapias & 15 & 3 & 1 & 4 & - & - & - & - \\
Manuais & & & & & & & & - \\
\hline Toga & 18 & 2 & - & - & - & - & - & - \\
\hline ToTAL & 121 & 44 & 26 & 43 & 1 & 12 & 1 & 1 \\
\hline & 48,6 & 17,7 & 10,4 & 17,3 & 0,4 & 4,8 & 0,4 & 0,4 \\
\hline
\end{tabular}

Tabela elaborada pelo autor, 2013.
Dentre os mais diferentes tipos de dor tratados pelas técnicas utilizadas pela Naturologia, alguns se destacam pelo número de pesquisas que os abordam (ver Tabela 3) e por serem recorrentes na atualidade (cervical, dismenorreia, dor de cabeça, lombar, parto). Outros tipos de dor possuem enorme grau de complexidade (AIDS, artrite reumatoide, câncer, doença de Gaucher). Mas o que a tabela 3 evidencia, é o grande interesse da ciência por tais técnicas, que podem ser ferramentas adjuvantes no combate e/ou controle desse sofrimento humano.

Tabela 3: Especificação da dor nos artigos

\begin{tabular}{|c|c|c|c|}
\hline Dor & $\begin{array}{l}\mathrm{N}^{\circ} \text { de } \\
\text { artigos }\end{array}$ & Dor & $\begin{array}{l}\mathrm{N}^{\circ} \text { de } \\
\text { artigos }\end{array}$ \\
\hline Abdominal & 1 & $\begin{array}{l}\text { Inserção de } \\
\text { agulhas }\end{array}$ & 4 \\
\hline AIDS & 1 & Laboral & 1 \\
\hline Artrite & 1 & Lombar & 28 \\
\hline $\begin{array}{l}\text { Artrite } \\
\text { reumatoide }\end{array}$ & 4 & Miofascial & 1 \\
\hline Câncer & 15 & Modulação da dor & 1 \\
\hline Cervical & 14 & $\begin{array}{l}\text { Músculo } \\
\text { esquelética }\end{array}$ & 5 \\
\hline Cólica infantil & 1 & $\begin{array}{l}\text { Neuropatia } \\
\text { periférica }\end{array}$ & 6 \\
\hline Colonoscopia & 2 & Ombro & 7 \\
\hline Dismenorreia & 19 & Osteoartrite & 8 \\
\hline $\begin{array}{l}\text { Doença de } \\
\text { Gaucher }\end{array}$ & 1 & Osteoartrose & 2 \\
\hline $\begin{array}{l}\text { Dor (não } \\
\text { específica) }\end{array}$ & 49 & Osteoporose & 1 \\
\hline Dor de cabeça & 14 & Parto & 14 \\
\hline Dor induzida & 3 & $\begin{array}{l}\text { Percepção da } \\
\text { dor }\end{array}$ & 1 \\
\hline Endoscopia & 1 & Pós-operatório & 13 \\
\hline Epicondilite & 1 & Pré-operatório & 1 \\
\hline Episitomia & 2 & Queimadura & 1 \\
\hline $\begin{array}{l}\text { Esclerose } \\
\text { múltipla }\end{array}$ & 1 & Raynald & 1 \\
\hline Fibromialgia & 12 & Reumáticas & 1 \\
\hline Gonartritis & 1 & $\begin{array}{l}\text { Síndrome do } \\
\text { piriforme }\end{array}$ & 1 \\
\hline Herpes zoster & 1 & $\begin{array}{l}\text { Síndrome túnel } \\
\text { do carpo }\end{array}$ & 2 \\
\hline Inflamação & 1 & $\begin{array}{l}\text { Síndrome } \\
\text { Guillain Barré }\end{array}$ & 1 \\
\hline $\begin{array}{l}\text { Infusão de } \\
\text { células tronco }\end{array}$ & 1 & $\begin{array}{l}\text { Temporoman- } \\
\text { dibular }\end{array}$ & 1 \\
\hline
\end{tabular}

Tabela elaborada pelo autor, 2013. 
Esta pesquisa trás à luz resultados positivos quanto à utilização das técnicas para o auxílio ao combate às afecções álgicas (Tabela 4). Merecem atenção os resultados indicando a redução do uso de medicamentos $(2,4 \%)$ e melhor resposta ao tratamento convencional $(0,8 \%)$, não pelos números apresentados, mas pelo impacto que isso pode ter no tratamento. Os números obtidos não deixam dúvidas sobre o auxílio de tais técnicas para tal propósito, pois a soma dos resultados favoráveis em relação ao alivio da dor (assinalados com asterisco na tabela 4 ) perfazem $84,3 \%$ do total de resultados pesquisados.

Tabela 4: Resultados obtidos na pesquisa

\begin{tabular}{|c|c|c|}
\hline Resultados & $\begin{array}{l}N^{\circ} \text { de } \\
\text { artigos }\end{array}$ & $\%$ \\
\hline Redução da dor ${ }^{*}$ & 64 & 25,7 \\
\hline Melhora significativa* & 31 & 12,5 \\
\hline Amenização dos sintomas* & 37 & 14,8 \\
\hline Redução - uso medicamentos ${ }^{\star}$ & 6 & 2,4 \\
\hline Aumento do autocontrole ${ }^{*}$ & 3 & 1,2 \\
\hline Duvidoso & 4 & 1,6 \\
\hline Pode aliviar a dor* & 24 & 9,7 \\
\hline Resultados positivos ${ }^{\star}$ & 41 & 16,4 \\
\hline Maior tolerância à dor ${ }^{*}$ & 2 & 0,8 \\
\hline Pouco significativo & 16 & 6,4 \\
\hline Sem benefícios & 7 & 2,8 \\
\hline Evidências insuficientes & 9 & 3,7 \\
\hline Não aceitação dos pacientes & 1 & 0,4 \\
\hline Não causam danos & 2 & 0,8 \\
\hline $\begin{array}{l}\text { Melhor resposta ao tratamento } \\
\text { convencional }^{*}\end{array}$ & 2 & 0,8 \\
\hline
\end{tabular}

Tabela elaborada pelo autor, 2013.

A comprovação da eficácia e a beneficência dos tratamentos foram observadas em 54,6\% dos artigos pesquisados (Tabela 5). A probabilidade de eficácia $(10,9 \%)$ fica atrelada à necessidade de mais estudos $(33,3 \%)$, demonstrando grandes possibilidades do aumento do índice de eficácia.
Tabela 5: classificação geral das técnicas pesquisadas

\begin{tabular}{lcc}
\hline Classificação & $\begin{array}{c}\text { No de } \\
\text { artigos }\end{array}$ & $\%$ \\
\hline Eficaz & 125 & 50,2 \\
\hline Pode ser eficaz & 27 & 10,9 \\
\hline Ineficaz & 3 & 1,2 \\
\hline Benéfica & 11 & 4,4 \\
\hline Necessita mais estudos & 83 & 33,3 \\
\hline
\end{tabular}

Tabela elaborada pelo autor, 2013.

\section{DISCUSSÃO}

Embora, dentre todos os artigos pesquisados, os referentes à acupuntura tenham se destacado em relação ao número de publicações, no presente trabalho esta técnica não recebeu destaque frente às outras técnicas citadas, pois a naturologia busca 0 sinergismo utilizando uma ou mais técnicas que se considere adequadas para cada caso, respeitando a individualidade de cada paciente.

Referente aos florais (vários sistemas foram pesquisados - Bach, Minas, Gaia, Bush Australiano, Califórnia), os artigos levantados mostravam sua utilização na amenização de diversos tipos de dor - parto, tanatologia, psíquicas, sociais, físicas, mas nenhum dos artigos pesquisados utilizava o floral como ferramenta principal no auxílio da dor. O mecanismo de ação destes medicamentos ainda não está elucidado e o número de estudos científicos sobre o assunto ainda é escasso na literatura e recebe críticas que enfatizam um possível efeito placebo. Porém, vários estudos realizados com animais descartam o efeito placebo, já que os mesmos são desprovidos de elementos neurofisiológicos responsáveis pela autossugestão $0^{35}$.

Existe um grande interesse em se elucidar os mecanismos de ação das técnicas utilizadas pela naturologia, como se pode observar na tabela 1 . O número reduzido de artigos referentes à fitoterapia, não se dá por este tópico possuir poucas pesquisas na literatura, mas pelo enfoque dado no presente trabalho, que procurou verificar a fitoterapia tradicional multissistêmica, que não se atem apenas no quadro álgico do paciente, observando também as causas e consequências advindas desse quadro, além de não trabalhar 
com o principio ativo isolado (foco da maioria das pesquisas) e sim a planta como um todo, principalmente na forma de tintura. O pensamento multissistêmico apesar de complexo é de simples entendimento - vários princípios ativos que, atuando em conjunto, potencializam o tratamento, atuando em mais de um sistema corpóreo ao mesmo tempo - porém existem grandes dificuldades no tocante às pesquisas para o entendimento dessa atuação.

Ainda na tabela 1, se pode observar que o Qigong e o Tai Chi também possuem um número reduzido de artigos. A explicação para tal fato pode estar na questão cultural, pois se trata de técnicas que necessitam de médio prazo para promoverem seus benefícios terapêuticos, questão esta que necessita ainda ser desenvolvida no ocidente, que vive no imediatismo do analgésico, sem se importar com seus efeitos colaterais. E também há carência do entendimento de que tais técnicas não proporcionam apenas redução da dor, mas também promoção e manutenção da saúde como um todo. Cabe também ao naturólogo um forte empenho de divulgação dos efeitos terapêuticos dessas práticas.

Os dados da presente pesquisa mostram claramente a eficácia das técnicas pesquisadas para o alívio dos mais diversos tipos de dor (tabelas 4 e 3 , respectivamente), mas há um detalhe importantíssimo que não deve passar despercebido aos olhos naturológicos, que é a não aceitação das técnicas pelos pacientes ou de seus familiares. Tal fato pode se dar pelo desconhecimento de tais procedimentos terapêuticos, por paradigmas étnicos, morais, religiosos e culturais, os quais deverão ser trabalhados com técnicas educacionais, a fim de promover a abertura do conhecimento para o rompimento das referidas barreiras, para que todos indistintamente (pacientes e familiares) se beneficiem desse aparato médico complementar.

Com olhar atento, ainda sobre a tabela 4 , observam-se dois aspectos relevantes: a diminuição do uso de medicamentos e a melhor resposta ao tratamento convencional. A importância da utilização de quantidades cada vez menores de medicamentos se faz relevante, pois pode amenizar os efeitos colaterais causados pelas drogas, diminuir custos gerados aos pacientes e às instituições de saúde, além de preservar o sistema imunológico (hipótese discutível na literatura $)^{36}$. A melhor resposta ao tratamento convencional dos quadros dolorosos corrobora com a ideia de sinergismo que a naturologia prega. Esse fato pode criar condições extremamente favoráveis de recuperação cada vez mais rápidas, menor tempo de internação, incentivo aos mecanismos fisiológicos de autorrecuperação, promovendo assim, a somatória, saúde, bem estar e qualidade de vida ${ }^{36}$.

A tabela 2 enfatiza a metodologia quantitativa como forma de pesquisa. Esse fato pode estar atrelado à questão de que tudo que pode ser quantificado possui maior status científico. Isso não significa que os outros métodos sejam piores ou melhores, mas talvez a pesquisa mista possa ser mais rica, pois permite recolher mais informações, tornando as metodologias complementares. A riqueza de dados promovida por essa mescla metodológica poderia contribuir em muito para elucidação, se não total, ao menos parcial, do mecanismo de ação de tais técnicas.

A grande carência de estudos comprobatórios mostrada na tabela 5 deve ser observada com muita atenção, pois pode ser o estopim inicial para que futuros naturólogos se empenhem cada vez mais na promoção de pesquisas que tragam à luz os mecanismos de ação de tais técnicas. Pesquisadores do Brasil e de todo o mundo estão em busca de tais comprovações, porém estes estudos deverão estar sobre os mais rigorosos crivos da ciência, para que sejam distanciadas as críticas que tendem a menosprezar, banalizar ou relegar ao segundo plano, práticas milenares presentes nos seios de todas as civilizações antigas, já defendidas por grandes estudiosos da humanidade como Hipócrates, Paracelso, Avicena, Hahnemann, só para citar alguns, e que ficaram adormecidas em prol de interesses mercantis.

\section{CONSIDERAÇÕES FINAIS}

As técnicas utilizadas pela naturologia para o auxílio ao tratamento dos quadros dolorosos se mostram, como evidenciou o presente trabalho, como ferramentas eficazes quando aplicadas de forma complementar ou autônomas (de acordo com o quadro de 
dor) e manipuladas por profissionais capacitados.

O percentual de artigos (6,8\%) em língua portuguesa se mostrou reduzido, o que demonstra a necessidade de empenho dos profissionais da naturologia e da área da saúde em geral, no desenvolvimento de pesquisas, para, se entender e aprimorar cada vez mais tais técnicas.

Foram analisados 249 artigos, resultantes de um rigoroso levantamento por meio virtual de mais de

\section{CONFLITOS DE INTERESSE}

Declararam não haver

\section{FONTES DE FINANCIAMENTO}

\author{
Nenhuma
}

\section{REFERÊNCIAS}

1. SBED - Sociedade brasileira para o estudo da dor. Hospital sem dor diretriz para implantação da dor como $5^{\circ}$ sinal vital. Disponível em: http://www.dor.org.br/profissionais/5_sinal_vital.asp - acesso em 10.04.2013

2. Carvalho MMMJ. Dor um estudo multidisciplinar. Summus editorial ltda, 1999; $2^{\text {a }}$ edição.

3. Silva AEM. Naturologia: Um dialogo entre saberes. Doutorado em ciências sociais, 2012. http://www.sapientia.pucsp.br/tde_busca/ arquivo.php?codarquivo=15262 - acesso em 21.04.2013

4. Ramachandran VS, Blakeslee S. Fantasmas no cérebro. Editora Record, 2004, 2a edição. http://xa.yimg.com/kq/ groups/18176607/569067002/name/livro\%2bos\%2bfantasmas\%2b no $\% 2 b c \% 25$ c3\%25a9rebro\%2b-\%2bv.\%2bs.\%2bramachandran, $\% 2$ bp.h.d.\%2be\%2bsandra.pdf - acesso em 07.04.2013.

5. Brasil. Portaria $n^{\circ} 971$, de 3 de maio de 2006. Ministério da Saúde. Disponível em: http://portal.saude.gov.br/portal/arquivos/pdf/ pnpic.pdf - acesso em 23.04.2013

6. Akiyama K. Práticas não convencionais em medicina no município de São Paulo. Tese de doutorado, 2004. Disponível em: http://www. teses.usp.br/teses/disponiveis/5/5137/tde-04042005-212807/pt-br. php - acesso em 28.04.2013.

7. Marquez JO. A dor e os seus aspectos multidimensionais. Cienc. Cult., São Paulo, v. 63, n. 2, Apr. 2011. http://cienciaecultura.bvs.br/ scielo.php?script=sci_arttext\&pid=S0009-67252011000200010\&ln $\mathrm{g}=\mathrm{en} \& \mathrm{nrm}=\mathrm{iso}$ - acesso em 01.05.2013

8. Teixeira MJ. Fisiopatologia da nocicepção e da supressão da dor. JBA, Curitiba, v.1, n.4, p.329-334, out./dez. 2001. http://www. dtscience.com/index.php/orthodontics_JBA/article/view/184 acesso em 28.04.2013.

9. Budó MLD, et al. A cultura permeando os sentimentos e as reações frente à dor. Disponível em: http://www.scielo.br/pdf/reeusp/ v4ln1/v41n1a04.pdf - acesso em 02.05.2013

10. Rizzardi CDL, Teixeira MJ, Siqueira SRDT. Espiritualidade e religiosidade no enfrentamento da dor. Disponível em: http://www.saocamilo-sp.br/pdf/mundo_saude/79/483e487.pdf acesso em 03.05.2013

11. Ernest E, White A. Acupuntura - uma avaliação científica. Editora Manole, 2001; $1^{\text {a }}$ edição

12. Wen TS. Acupuntura clássica chinesa. Editora Cultrix; 2006.

13. Shi-Yng J, Wan-Cheng J. Manual Prático de Auriculopuntura. Editora Roca, 2012; $1^{\text {a }}$ edição.

14. Kit WK. Chi Kung (Quiogong) - Para a saúde e a vitalidade. Editora Pensamento; 1997.
1500 trabalhos que, após uma análise prévia, descartou os que não se mostravam pertinentes ao tema. Os Estados Unidos se mostram pioneiros nas pesquisas dessa área com 77 artigos (30,9\%), seguido do Reino Unido e China com 20 artigos (8,0\%) cada. Surpreendente é a posição do Brasil ( $3^{\circ}$ no ranking) ao lado da Alemanha. Fica destacado o interesse mundial (27 países - praticamente dos cinco continentes) sobre 0 assunto.
15. Hong JZ, Becchio J. Zhi neng qi gong de Pang He Ming - A saúde pela ginástica chinesa. Editora Andrei, 2005.

16. McGilvery C, Reed J, Mehta M. Massage, aromatherapy \& yoga. Editora Lorenz Books; 1999.

17. Lederman E. Fundamentos da terapia manual. Editora Manole, 2001; 1 1 edição.

18. Vorkapic GF. A Ciência da yoga. Revista mente cérebro. Disponível em: http://www2.uol.com.br/vivermente/reportagens/a_ciencia_ da_ioga.html acesso em 15.09.2013

19. Forde RQ. O Livro da medicina tibetana. Editora Pensamento; 2008.

20. Masselli MR, et al. O Shiatsu como terapêutica alternativa em portadores de distúrbios osteomusculares relacionados ao trabalho. Rev. dor; 11(3), jul.-set. 2010. Disponível em: http://bases.bireme. br/cgibin/wxislind.exe/iah/online/?IsisScript=iah/iah.xis\&src=goo gle\&base $=$ LILACS\&lang $=$ p\&nextAction $=$ lnk\&exprSearch $=562469$ \&indexSearch=ID - acesso em 23.09.2013.

21. Hopking A. Cura esotérica. Editora Pensamento, 2008.

22. Brennan BA. Mãos de luz. Editora pensamento, 2009; $23^{a}$ edição.

23. Oliveira RMJ. Avaliação de efeitos da prática de impostação de mãos sobre os sistemas hematológico e imunológico de camundongos machos. Dissertação apresentada à faculdade de medicina da universidade de São Paulo para obtenção do título de mestre em ciências, 2003. Disponível em: http://www.amebrasil. org.br/html/Disserta_o_de_Mestrado__Oliveira_RMJ.pdf acesso em 26.09.2013

24. Price S. Aromaterapia para doenças comuns. Editora Manole, 1999.

25. Price S. Aromaterapia e as emoções. Editora Bertrand Brasil, 2006; $2^{a}$ edição.

26. Wagner H, Weisenauer M. Fitoterapia: fitofármacos, farmacologia e aplicações clínicas. Editora Pharmabooks, 2006.2[ edição.

27. Cavaleiro C. Plantas aromáticas e óleos essenciais em farmácia e medicina. Laboratório de farmacognosia, $\mathrm{CEF}$ / faculdade de farmácia, Universidade de Coimbra, Portugal, 2007. Disponível em: http://cbv. fc.ul.pt/PAM/pdfsLivro/CarlosCavaleiro.pdf - acesso em 27.09.2013.

28. Machado BFMT, Junior AF. Óleos essenciais: aspectos gerais e usos em terapias naturais. Unisul; Cadernos acadêmicos, Tubarão, 3, n. 2, p. 105-127, 2011. Disponível em: www.portaldeperiodicos.unisul. br/index.php/Cadernos.../article/.../671 - acesso em 26.09.2013

29. Vanaclocha B, Folcarà SC. Fitoterapia - Vadimecum de prescripcion. Editora Masson, 2003; 4a edição

30. Carvalho JCT. Formulário médico - farmacêutico de fitoterapia. Editora ciência Brasilis, 2005

31. Yunes RA, Pedrosa RC, Filho VC. Fármacos e fitoterápicos: a 
necessidade do desenvolvimento da indústria de fitoterápicos e fitofármacos no Brasil. Quim. Nova, Vol. 24, No. 1, 147-152, 2001. Disponível em: http://www.scielo.br/pdf/qn/v24n1/4464.pdf acesso em 30.09.2013.

32. Alonso J. Tratado de fitofarmacos y nutraceuticos. Corpus editoria y distribuidora, 2007.

33. Gomes L, Pereira MM, Assumpção LOT. Benefícios do tai chi chuan em idosos. Revista Digital, Buenos Aires, ano 10, n78, nov. 2004 Disponível em: http://www.efdeportes.com/efd78/taichi.htm acesso em 27.09.2013

34. Külkamp W, Dario AB, Gevaerd MS, Domenech SC. Artrite reumatóide e exercício físico: resgate histórico e cenário atual. Tese (Mestrado em ciências do movimento humano). UDESC, Santa Catarina, 2009. Disponível em: http://periodicos.ufpel.edu.br/ojs2/ index.php/RBAFS/article/view/755 - acesso em 03.10.2013.
35. Souza MM, Garbeloto M, Denez K, Mangrich IE. Avaliação dos efeitos centrais dos florais de Bach em camundongos através de modelos farmacológicos específicos. Revista brasileira de farmacognosia. 16(3): 365-371, Jul./Set. 2006. Disponível em: http://www.scielo.br/scielo.php?script=sci_arttext\&pid=S0102 695X2006000300014 - acesso em 27.10.2013.

36. Garcia JBS, Cardoso MGM, Santos MC. Opióides e o sistema imunológico: relevância clínica. Revista brasileira de anestesiologia 2012; 62:5: 709-718. Disponível em: http://www.scielo.br/pdf/rba/ v62n5/v62n5a10.pdf - acesso em 29.10.2013. 